\title{
Gender Identity Salience and Perceived Vulnerability to Breast Cancer
}

\section{Steven Sweldens, Stefano Puntoni, and Nader Tavassoli}

\begin{tabular}{|l|l|}
\hline \multicolumn{2}{|l|}{ ERIM REPORT SERIES RESEARCHINMANAGEMENT } \\
\hline ERIM Report Series reference number & ERS-2008-063-MKT \\
\hline Publication & October 2008 \\
\hline Number of pages & 24 \\
\hline Persistent paper URL & http://hdl.handle.net/1765/13613 \\
\hline Email address corresponding author & ssweldens@rsm.nl \\
\hline Address & Erasmus Research Institute of Management (ERIM) \\
& RSM Erasmus University / Erasmus School of Economics \\
& Erasmus Universiteit Rotterdam \\
& P.O.Box 1738 \\
& 3000 DR Rotterdam, The Netherlands \\
& Phone: $\quad+31104081182$ \\
& Fax: $\quad+31104089640$ \\
& Email: info@erim.eur.nl \\
& Internet: $\quad$ www.erim.eur.nl \\
\hline
\end{tabular}

Bibliographic data and classifications of all the ERIM reports are also available on the ERIM website: www.erim.eur.nl 


\section{ERASMUS RESEARCH INSTITUTE OF MANAGEMENT}

\section{REPORT SERIES}

\section{RESEARCH IN MANAGEMENT}

\begin{tabular}{|c|c|}
\hline \multicolumn{2}{|c|}{ ABSTRACT AND KEYWORDS } \\
\hline Abstract & $\begin{array}{l}\text { Contrary to predictions based on cognitive accessibility, heightened gender identity salience } \\
\text { resulted in lower perceived vulnerability and reduced donation behavior to identity-specific risks } \\
\text { (e.g., breast cancer). No such effect was manifest with identity-neutral risks. Establishing the } \\
\text { importance of self-identity, perceived breast cancer vulnerability was lower when women were } \\
\text { primed with their own gender, but not with the general category of gender. Establishing the } \\
\text { involvement of unconscious defense mechanisms, fear appraisal prior to the risk rating task } \\
\text { eliminated the effect of a gender identity prime on perceived breast cancer vulnerability. The } \\
\text { findings have direct implications for health communication and donation campaigns. }\end{array}$ \\
\hline Free Keywords & gender identity salience, breast cancer vulnerability, awareness campaigns \\
\hline Availability & $\begin{array}{l}\text { The ERIM Report Series is distributed through the following platforms: } \\
\text { Academic Repository at Erasmus University (DEAR), DEAR ERIM Series Portal } \\
\text { Social Science Research Network (SSRN), SSRN ERIM Series Webpage } \\
\text { Research Papers in Economics (REPEC), REPEC ERIM Series Webpage }\end{array}$ \\
\hline Classifications & $\begin{array}{l}\text { The electronic versions of the papers in the ERIM report Series contain bibliographic metadata } \\
\text { by the following classification systems: } \\
\text { Library of Congress Classification, (LCC) LCC Webpage } \\
\text { Journal of Economic Literature, (JEL), JEL Webpage } \\
\text { ACM Computing Classification System CCS Webpage } \\
\text { Inspec Classification scheme (ICS), ICS Webpage }\end{array}$ \\
\hline
\end{tabular}




\title{
GENDER IDENTITY SALIENCE AND PERCEIVED VULNERABILITY
}

\author{
TO BREAST CANCER
}

\section{STEVEN SWELDENS}

Rotterdam School of Management, Erasmus University

\author{
STEFANO PUNTONI \\ Rotterdam School of Management, Erasmus University
}

\section{NADER TAVASSOLI*}

London Business School

\begin{abstract}
*Steven Sweldens is a Ph. D. candidate in Marketing and Stefano Puntoni is Assistant Professor of Marketing at the Rotterdam School of Management, Erasmus University, P.O. Box 1738, 3000 DR Rotterdam (ssweldens@rsm.nl, spuntoni@rsm.nl). Nader Tavassoli is Professor of Marketing, Chair Marketing Subject Area, London Business School, Regent's Park, London NW1 4SA UK (ntavassoli@london.edu).
\end{abstract}




\begin{abstract}
Contrary to predictions based on cognitive accessibility, heightened gender identity salience resulted in lower perceived vulnerability and reduced donation behavior to identity-specific risks (e.g., breast cancer). No such effect was manifest with identity-neutral risks. Establishing the importance of self-identity, perceived breast cancer vulnerability was lower when women were primed with their own gender, but not with the general category of gender. Establishing the involvement of unconscious defense mechanisms, fear appraisal prior to the risk rating task eliminated the effect of a gender identity prime on perceived breast cancer vulnerability. The findings have direct implications for health communication and donation campaigns.
\end{abstract}


Breast cancer is one of the world's leading causes of death and breast cancer awareness campaigns aim to increase women's risk awareness and promote early screening behavior. Health campaigns aimed at increasing women's breast cancer awareness often stress women's vulnerability to breast cancer using images and appeals related to the female sex and to femininity. Estimates of personal risk are constructed by individuals based on environmental cues and personal experience. In particular, personal risk perceptions are closely tied to individuals' sense of self due to the link between aspects of one's self-concept (e.g., lifestyle, age or gender) and actual risk. Despite the large body of literature devoted to understanding the psychological processes involved in the estimation of perceived vulnerability, the relationship between risk estimates and self-identity is still unclear.

This paper explored how inherent characteristics of a risk interact with selfidentity salience to influence estimates of perceived vulnerability. In particular, we investigated how and under which conditions the salience of a certain identity trait (e.g., gender) can influence one's perceived susceptibility to risks associated with this trait (e.g., breast cancer). Two alternative theoretical accounts-cognitive accessibility and defense mechanisms-provide opposing predictions with regard to the direction of the influence of identity salience in perceived risk.

Cognitive accessibility predicts an increase in gender-related risk perception following an increase in gender salience. Contextual factors that increase the salience of a dimension of self-identity should increase the accessibility of knowledge structures associated with this dimension and result in higher likelihood estimates for risks that are associated to this activated dimension through the operation of judgmental heuristics. For example, increased (decreased) accessibility of AIDSrelated information had a positive (negative) effect on associated risk perceptions (Raghubir and Menon 1998). The cognitive accessibility account therefore predicts that increased gender salience should increase estimates of gender-specific risks.

A different line of reasoning, based on defense mechanisms, leads to the opposite prediction for identity aspects that are central to the self. The sexual self is a central aspect of women's multifaceted self and a disease such as breast cancer is inextricably bound to women's perception of their gender identity. Under conditions of heightened gender identity salience, the thought of contracting breast cancer may be perceived as especially threatening. Consequently, defensive mechanisms-which are intimately related to ego threat-may occur in these conditions, leading to a minimization of subjective risk estimates. For example, participants who were made to believe they suffered from a fictitious enzyme deficiency evaluated this deficiency as less serious than controls (Jemmott, Ditto, and Croyle 1986) and personal relevance increases the likelihood that threatening health messages are defensively processed (Liberman and Chaiken 1992).

To summarize, two distinct accounts make opposing predictions regarding the effect of identity salience on identity-specific risk perception. Cognitive accessibility predicts that heightening women's gender identity increases perceived vulnerability to risks such as breast cancer. A motivational defense mechanism account predicts instead that when a central aspect of the self (e.g., women's gender) is made more salient, threats (e.g., breast cancer) to this aspect are likely to trigger defensive mechanisms (e.g., risk minimization). Neither account predicts an effect of increased gender salience on gender-neutral risks. 
We conducted a series of experiments with female participants to test these theories. Significant interactions and simple effects provide evidence for the defensive mechanism account and explored boundary conditions for the effect of identity salience on perceived risk. In experiment 1,2 , and 4 identity salience was manipulated using an essay writing task. Relative to a control condition, in the gender prime condition we observed a decrease in women's perceived risk of contracting breast cancer (experiments 1 and 4) whereas no effect was evident on risks without a link to gender identity. Behavioral implications were apparent in experiment 2 , in which we found that gender priming leads to a decrease in donations to research on ovarian cancer treatment. Confirming the role of nonconscious defensive mechanisms, fear appraisal prior to the risk rating task muted the effect of gender identity salience on risk perceptions (experiment 4). In experiment 3 we used a more subtle gender priming task in which participants determined the gender of Dutch words. Establishing the importance of self-identity, perceived breast cancer vulnerability was lower when women were primed with their own gender, but not with the general category of gender.

These experiments contribute to literature on subjective risk estimates, defensive mechanisms and cognitive priming. Moreover, the results have implications for the design of health campaigns. Breast cancer awareness campaigns almost inevitably stress womanhood or women's sense of gender identity and along with it the relative importance of this identity aspect for their self-concept. Our findings indicate that an increase in gender identity salience can trigger defensive mechanisms of risk minimization, thus potentially attenuating or even reversing a campaign's intended consequences. The results of the experiments provide a number of suggestions on how to reduce the likelihood of defensive mechanisms interfering with the intended aim of health campaigns.

Jemmott, John B., Peter H. Ditto, and Robert T. Croyle (1986), "Judging Health Status: Effects of Perceived Prevalence and Personal Relevance," Journal of Personality and Social Psychology, 50 (5), 899-905.

Liberman, Akiva and Shelly Chaiken (1992), "Defensive Processing of Personally Relevant Health Messages," Personality and Social Psychology Bulletin, 18 (December), 669-679.

Raghubir, Priya and Geeta Menon (1998), "AIDS and Me, Never the Twain Shall Meet: The Effects of Information Accessibility on Judgments of Risk and Advertising Effectiveness," Journal of Consumer Research, 25 (June), 52-63. 


\section{GENDER IDENTITY SALIENCE AND PERCEIVED VULNERABILITY TO BREAST CANCER}

Breast cancer is one of the world's leading causes of death and, as with many diseases, early diagnosis can often significantly improve chances of survival. Because judgments of vulnerability to health risks are generally regarded as a necessary condition for precautionary behavior, breast cancer awareness campaigns aim to increase women's risk awareness and promote early screening behavior.

Personal risk perceptions are also closely tied to individuals' sense of self due to the link between aspects of one's self-concept (e.g., lifestyle, age or gender) and actual risk. We examine how the situational salience of women's own gender affects

perceived vulnerability to breast cancer. This is an issue that is especially relevant to health communication practices because appeals warning against breast cancer tend to make gender identity salient through text (e.g., "If you are a woman, what you're about to read could save your life..."), symbols (e.g., the pink ribbon), or images (e.g., a naked woman covering her removed breast).

\section{IDENTITY SALIENCE AND RISK PERCEPTIONS}

Research on self-identity highlights the influence of situational factors and of the social environment on the self-concept (Markus and Wurf 1987). According to the notion of a malleable self-concept, all individuals possess a number of different selves related to the various roles and goals endorsed in life. Each of us has a repertoire of social identities ranging from clearly delineated group memberships (e.g., soccer club member) to abstract social categories (e.g., liberal). The salience of these different identity aspects is dependent on social circumstances, with both motivational (Markus 
and Nurius 1986) and information processing consequences (Markus and Kunda 1986).

Medical risk can often be predicted by the presence of personal traits and lifestyles. For example, one's gender predicts susceptibility to breast cancer and smoking predicts susceptibility to lung cancer. To the extent that a personal trait or lifestyle forms an important part of an aspect of self-identity, situational variability in identity salience should influence perceived vulnerability to risks associated to this aspect of identity. Despite the importance of considering the role of self-identity in models of risk perception, little is known about the influence of identity salience on risk. We identified two alternative theoretical accounts—cognitive accessibility and defense mechanisms - that provide opposing predictions with regard to the direction of this influence.

Cognitive Accessibility Predicts Increased Perceived Vulnerability. Cognitive accessibility predicts an increase in gender-related risk perception following an increase in gender salience. Contextual factors that increase the salience of a dimension of self-identity should increase the accessibility of knowledge structures associated with this dimension due to the principle of spreading of activation (McClelland 2000). The increased accessibility should then result in higher likelihood estimates for risks that are associated to this activated dimension through the operation of judgmental heuristics.

According to the availability heuristic, the likelihood of an event can be estimated based on the ease with which operations of retrieval, construction or association can be performed (Tversky and Kahneman 1973). A variety of mechanisms can underlie the availability heuristic (Hertwig, Pachur, and Kurzenhauser 2005). An increased accessibility of specific instances can give rise to 
higher subjective risk estimates. For example, the number of recalled occurrences of breast cancer in one's network of acquaintances can be used as a cue for estimating one's personal risk. The actual operation of retrieval, however, is not necessary for the availability heuristic. Cognitive accessibility can also be assessed by the perceived ease with which operations of retrieval or construction could be performed (Tversky and Kahneman 1973), what Hertwig et al. (2005) labeled the fluency mechanism.

The availability heuristic is a cornerstone of literature on judgment and decision making, and its importance has not escaped consumer researchers in the area of risk perception. For example, increased (decreased) accessibility of AIDS-related information had a positive (negative) effect on associated risk perceptions (Raghubir and Menon 1998). The cognitive accessibility account therefore predicts that increased gender salience should increase accessibility of gender-related knowledge structures and hence increase estimates of gender-specific risks.

Defense Mechanisms Predict Decreased Perceived Vulnerability. A different line of reasoning, based on defense mechanisms, leads to the opposite prediction of a cognitive accessibility account for identity aspects that are central to the self. The sexual self is a central aspect of women's multifaceted self (Andersen and Cyranowski 1994) and a disease such as breast cancer is inextricably bound to women's perception of their gender identity (Fallowfield and Hall 1991). For cultural, developmental and sexual reasons, the breast plays a core role in female identity formation (Hall 1997). Therefore we hypothesize that under conditions of heightened gender identity salience, the thought of contracting breast cancer will be perceived as especially threatening. Consequently, defensive mechanisms - which are intimately related to ego threat - should occur in this condition, leading to a minimization of subjective risk estimates. 
Well documented defense mechanisms in risk settings are denial strategies such as minimizing threat, building perceptual defenses, and using personal fantasies and ridicule (Baumeister, Dale, and Sommer 1998). For example, participants who were made to believe they suffer from a fictitious enzyme deficiency evaluated this deficiency as less serious than controls (Jemmott, Ditto, and Croyle 1986) and personal relevance has been found to increase the likelihood that threatening health messages are defensively processed (Liberman and Chaiken 1992). Such defensive processing can be avoided by self-affirmation in unrelated domains, corroborating the link between defensive mechanisms and ego threat (Harris and Napper 2005).

To summarize, two distinct accounts make opposing predictions regarding the effect of identity salience on identity-specific risk perception. Cognitive accessibility predicts that heightening women's gender identity increases perceived vulnerability to risks such as breast cancer. A motivational defense mechanism account predicts the opposite. When a central aspect of the self (e.g., women's gender) is made more salient, threats (e.g., breast cancer) to this aspect are likely to trigger defensive mechanisms (e.g., risk minimization). Neither account predicts an effect of increased gender salience on gender-neutral risks.

\section{EXPERIMENT 1}

Experiment 1 was designed to assess the effect of heightened gender salience on women's perceived susceptibility to breast cancer - a gender-specific risk - and several gender-neutral risks.

Method

Participants and Design. Participants were 37 female students at a Dutch university who participated in an online study in return for entering a lottery (median and modal age $<21)$. Participants completed two purportedly unrelated studies. The 
first contained a manipulation of gender salience while the second assessed perceived vulnerability to a number of risks. The design was therefore a mixed 2 (gender salience: gender-prime vs. control) x 2 (risk type: gender-specific vs. gender-neutral) design with gender salience manipulated between subjects.

Procedure. Participants were randomly emailed a link to one of two versions of a website with the incentive of a lottery offering a $10 \%$ chance of receiving a $€ 20$ voucher from a popular online book retailer. The two studies were presented as independent (e.g., using different graphical elements) and students were assured that they would receive the lottery ticket for the first study even if they did not complete the second one (one person did not). Participants in the gender-prime (control) condition wrote two essays on the influence of their gender (education) on decision making and interpersonal relationships. A pre-test—not reported here due to space restrictions - confirmed the validity of this gender priming procedure by testing its effect on femininity and masculinity scores as measured by established gender identity measures (e.g., Bem 1981). An allegedly unrelated second study was then introduced as an investigation of people's vulnerability to accidents, injuries, and diseases. Participants rated their perceived vulnerabilities to nine gender-neutral risks (e.g., plane crash, heart attack, diabetes) and one gender-specific risk (breast cancer) on a scale ranging from 1 ("very unlikely for me") to 7 ("very likely for me"). On the final page of the website, participants were asked to report their age, to indicate whether they had been interrupted at any time during the completion of the two studies, and to guess the purpose of the study.

Results and Discussion

No participant made a connection between the two parts of the study. Risk scores for the nine gender-neutral items were averaged. Results were analyzed using a 
2 (priming condition) $\times 2$ (risk type) ANOVA with repeated measures on the second factor. This analysis revealed a main effect of risk type, $F(1,34)=47.76, p<.0001$ : participants felt more at risk for breast cancer $(M=4.58, S D=1.34)$ than for the gender-neutral risks $(M=3.30, S D=0.81)$. There was no significant main effect of the experimental priming condition $(p>.15)$. There was a significant risk type by priming condition interaction, $F(1,34)=6.36, p<.05$. This was consistent with a defense mechanism explanation as opposed to a cognitive accessibility account. Women in the gender-prime condition reported lower breast cancer risk estimates $(M$ $=4.07, S D=1.28)$ than women in the control condition $(M=4.95, S D=1.28), t(34)=$ $2.04, p<.05$, whereas there was no effect of the priming condition on the average of the other risks $(M=3.30, S D=0.80$ vs. $M=3.30, S D=0.84)$. To validate the averaging across gender-neutral risks, we computed separate univariate ANOVAs for each included risk. The only significant effect of the gender priming procedure was observed for the breast cancer risk estimate, $F(1,34)=4.18, p<.05$, whereas there was no effect of gender priming on any of the other risks ( $p$ s $>.29)$. Given the novelty of these findings, we carried out a replication using participants from a different country. A study using 69 female students at a UK university led to analogous results to those of experiment 1 (for the priming by risk type interaction, $F(1,67)=4.20, p<$ $.05)$.

\section{EXPERIMENT 2}

The goal of experiment 2 was to examine the effect of gender priming on real donations to different types of cancer research. In particular, we examined whether, paralleling the effect on risk perceptions observed in experiment 1 , gender priming can lead to an effect on actual donation behavior. We also used a different disease, 
ovarian cancer, which is a less common form of cancer than breast cancer but one that is also central to women's sexual identities.

Method

Participants were 26 female students at a UK business school (median and modal age was 21-25 years) who participated in exchange for an actual contribution to Cancer Research UK. There was one between-subjects factor: gender salience. The study was conducted online. As in the previous experiment, participants in the genderprime (control) condition wrote two essays about the influence of their gender (education) on decision making and on interpersonal relationships. They were informed that, in exchange for their help, $£ 5$ would be donated to Cancer Research UK and were then asked to select the type of cancer research that they wanted to sponsor. Six options were provided: gallbladder-, larynx-, leukemia-, lung-, ovarian-, or prostate cancer. Participants were then asked to indicate their age, whether they were interrupted while completing the study, and to guess the purpose of the study. Results and Discussion

One participant guessed the purpose of the study and was omitted from the analysis. Four participants indicated they had been interrupted during the study. The majority (15 out of 25$)$ of participants donated to research on ovarian cancer so we dichotomized the response into donating to ovarian cancer research versus not. A logistic regression modeling the probability of donating to ovarian cancer research as a function of the experimental condition and the interruption covariate shows a significant effect of condition, Wald $\chi^{2}(1)=4.13, p<.05$. Fewer participants in the gender priming condition donated to ovarian cancer (42\%) than in the control condition (77\%). This experiment showed that the operation of defensive mechanisms in response to gender priming has behavioral consequences. Gender priming led to a 
decrease in the amount of money that participants decided to donate to ovarian cancer research. This result also has substantive implications for health campaigns aimed at fund raising.

\section{EXPERIMENT 3}

Experiments 1 and 2 provide evidence consistent with a defense mechanism but contrary to the predictions of the cognitive accessibility account. The latter suggests that priming people with gender should result in an increased accessibility of gender-related constructs which, in turn, should lead to higher perceived risk estimates for gender-related risks. Experiment 3 explored boundary conditions for the occurrence of a defense mechanism while simultaneously testing for the presence of a countervailing cognitive mechanism. A defense mechanism of risk minimization should only manifest itself in the case of ego threat, that is, when one's own gender identity is made more salient. The cognitive accessibility effect should manifest itself when gender is activated as a general cognitive category, that is, without necessarily requiring specific reference to one's own gender. Therefore, the primary goal of experiment 3 was to devise a priming procedure which would disentangle the two processes.

In contrast to the flexible essay writing manipulation of the previous experiments, we employed a highly abstract manipulation of gender salience in which participants were asked to guess the gender of a series of Dutch words. In Dutch a word's gender is mostly difficult to determine, requiring elaborate thinking. To determine a word's gender one must try to substitute the word in a sentence by gender-disambiguating pronouns like 'him' or 'her'. Even then, errors can occur frequently. We therefore used the determination of words' gender as a priming procedure to prime either the general cognitive category of gender (general-gender 
condition) or women's own gender (own-gender condition). The breast cancer risk estimates in these conditions were also compared to those in a control condition where participants rated the abstractness versus concreteness of a noun. Due to the increase in cognitive accessibility of gender-related constructs, breast cancer risk estimates should be highest in the general-gender condition. The operation of defense mechanisms should cause breast cancer risk estimates to be lower in the own-gender than in the control and general-gender conditions.

Method

Participants and Design. Participants were 122 female undergraduate students at a Dutch university (age: $M=22, S D=4.21$ ) who participated in this experiment as part of a series of studies in return for a small reward (candy). Experiment 3 used a mixed 3 (priming: general-gender vs. own-gender vs. control) by 2 (risk type: genderspecific vs. gender-neutral) design, with the first factor manipulated between-subjects and the second within-subjects.

Procedure. Participants completed the study in individual cubicles. The experiment used a pool of 30 male and 30 female words randomly selected from the Woordenlijst Nederlandse Taal (Nederlandse Taalunie 2005), the official Dutch vocabulary. Examples of male words are "corridor" ("gang”), "distance” (“afstand"), "fish" ("vis"), and "magnet" ("magneet"). Examples of female words are "factory" (“fabriek"), "house” (“woning”), “music” (“muziek”), and "politics” (“politiek”). Participants were randomly assigned to one of the three priming conditions. In the general- and own-gender conditions, they were asked to guess the gender of 16 words by substituting them in a sentence with a gender-disambiguating pronoun, and to report each sentence before confirming the gender of the word. In the own-gender condition, unbeknownst to participants, the 16 words were randomly selected from the 
list of 30 female words. In the general-gender condition, participants had to determine the gender of 8 randomly drawn words from the list of 30 male words and 8 randomly drawn words from the list of 30 female words. Participants in the control condition were instead asked to rate the abstractness of all 60 words in the database. Next, participants were thanked for their cooperation so far and told that the next part of the research session was a study exploring perceived vulnerability to personal risks.

Participants had to indicate their subjective probability of suffering in the future from heart attack, diabetes, breast cancer and hepatitis C. As in experiments 1 and 2, we used a 7-point scale with the endpoints marked as "very unlikely for me" and "very likely for me". At the end of the experiment participants were asked to guess the purpose of the study.

Results

No participant expressed a suspicion about the link between the word task and the risk ratings study. Moreover, no participant in the own-gender condition noted the absence of male words. The data were analyzed using a 3 (priming condition) by 2 (risk type) ANOVA, with the second factor as a repeated measure. The main effect of experimental condition was marginally significant, $F(2,119)=2.96, p<.06$, with the average estimates of all risks lower in the own-gender $(M=3.42, S D=1.22)$ than the general-gender $(M=3.94, S D=1.00)$ and control $(M=3.87, S D=0.87)$ conditions. The main effect of risk type was significant, $F(1,119)=120, p<.0001$, with breast cancer risk estimates $(M=4.39, S D=1.45)$ higher than the average of other risk estimates $(M=3.07, S D=1.07)$. Most importantly, the hypothesized priming condition by type of risk interaction qualified these main effects, $F(2,119)=5.41, p<$ .01. Detailed contrast analyses (reported below) showed that priming moderated the 
breast cancer risk estimates but not the average of the other risks (for these risks, all $p$ s > .30); see Figure 1 .

FIGURE 1: Priming by risk type interaction in experiment 3

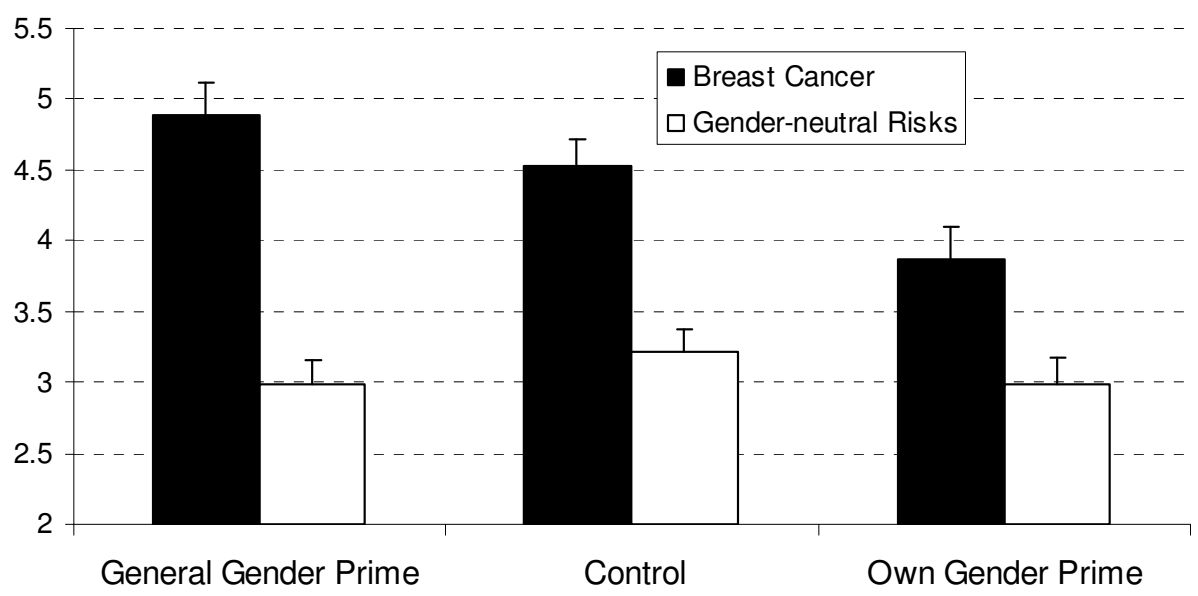

As hypothesized, and confirmed by a significant linear trend test, $t(119)=$ $3.23, p<.01$, breast cancer risk estimates were highest in the general-gender condition $(M=4.89, S D=1.35)$ and lowest in the own-gender condition $(M=3.86, S D=1.58)$, with the control condition falling in between $(M=4.52, S D=1.23)$. Planned contrasts revealed that breast cancer risk estimates were significantly lower in the own-gender condition than in the control condition, $t(119)=2.29, p<.05$. However, although in the expected direction, the difference between the general-gender and control conditions was not significant, $t(119)=1.15, p=.25$.

Discussion

Experiment 3 served two purposes. First, we wanted to establish boundary conditions for the operation of defense mechanisms. Second, we wanted to generalize the effect of gender identity salience on own-gender risk estimates with a different gender priming procedure. Specifically, we reasoned that for these defense mechanisms to occur, participants must be primed with their own gender. When 
gender is primed as a general cognitive category, we expected that breast cancer risk estimates would increase due to the increased accessibility of gender-related constructs and the relatively lower intensity of ego threat. Though a planned contrast failed to provide direct support for the latter, a linear trend analysis provided support for this conjecture: women's breast cancer risk perceptions were lowest when they were specifically primed with their own gender and highest when primed with the general cognitive category of gender, with the risk perceptions in a control condition falling in between.

Experiment 3 also reduces the possibility that the observed effects are cognitive rather than motivational in nature, namely that they are the result of a contrast effect. Previous research has shown that extreme primes can lead to opposite effects from moderate primes (Herr, Sherman, and Fazio 1983). In experiments 1 and 2, the essay-writing manipulation resulted in a supraliminal and possibly extreme prime, one that might have led to a contrast explainable by a cognitive accessibility account. The subtle, if not subconscious, manipulation in experiment 3 makes this explanation unlikely.

\section{EXPERIMENT 4}

Although experiment 3 provides more conclusive evidence for the unconscious nature of the breast cancer risk minimization resulting from gender priming, direct evidence that this effect stems from a defensive process in response to threat is still lacking. We suggested that the effect is driven by an unconscious feeling of threat in response to breast cancer that is elevated in women who have been gender primed. If this is the case, it should be possible to neutralize the effect by making women conscious of their fear of the disease. Research on ego defense has argued that defensive processes can not be effective if the defending person becomes aware of the 
process (Cramer 2000; Lazarus 2000). More generally, in their Appraisal-Tendency Framework for emotional carryover effects on risk perceptions, Han, Lerner and Keltner (2007) argued that these emotional influences will disappear (or be reversed due to overcorrection) when people become aware of them, consistent with a rich body of research on the use of affect as information (e.g., Schwarz and Clore 1983). The current study therefore tests the prediction that fear appraisal prior to the risk rating task eliminates the effect of gender priming on breast cancer risk estimates. Method

Participants and Design. One hundred and fifteen female students at a large Southeastern US university participated in the current study for course credit (age: $M$ $=20.2, S D=1.65$ ). The design of the study was a mixed 2 (priming: gender vs. control) by 2 (order of tasks: fear ratings before risk ratings vs. vice versa) by 2 (risk type: gender-specific vs. gender-neutral) with the first two factors manipulated between subjects and the third within-subjects.

Procedure. The experiment was conducted in a behavioral lab embedded in a series of studies. As gender priming manipulation we used again the essay writing task. In the seemingly unrelated subsequent study, we investigated participants' perceived level of fear and risk for seven negative events, one target (breast cancer) and six fillers (e.g., heart attack, diabetes, and Alzheimer's disease). Both fear and risk ratings were assessed on seven-point scales and administered on a per event basis (with either risk or fear first depending on experimental condition). Order of events was randomized with the restriction that breast cancer was never assessed first. Results

A repeated-measures ANOVA was consistent with our theorizing showing that assessing fear ratings first eliminates the interaction effect demonstrated across 
previous experiments. The main effect of risk type was significant, with breast cancer risk $(M=4.44, S D=1.49)$ higher than the gender-neutral risks $(M=3.47, S D=0.96)$, $F(1,111)=69.16, p<.0001$. There was a significant interaction between risk type and priming, $F(1,111)=5.18, p<.03$. Breast cancer risk perceptions were lower in the gender prime $(M=4.20, S D=1.63)$ than in the control condition $(M=4.76, S D=$ $1.22), F(1,111)=3.65, p<.06$, with no effects on the average of the other risks $(p>$ .82). Most importantly, this effect was further moderated by a three-way interaction that included the order-of-tasks manipulation, $F(1,111)=5.05, p<.03$. Planned interaction contrasts show that the priming manipulation only had an effect on the breast cancer risk perceptions when risk perceptions were assessed first, with breast cancer risk perceptions lower after the gender prime $(M=3.97, S D=1.68)$ than in the control condition $(M=4.85, S D=1.26), F(1,111)=5.36, p=.02$. This effect was absent when fear ratings were assessed first $(p>.65)$. No effects were significant for the average of the other risks (both $p$ s $>.29$ ); see Figure 2.

FIGURE 2: Risk Estimates Gender Prime Interaction in experiment 4
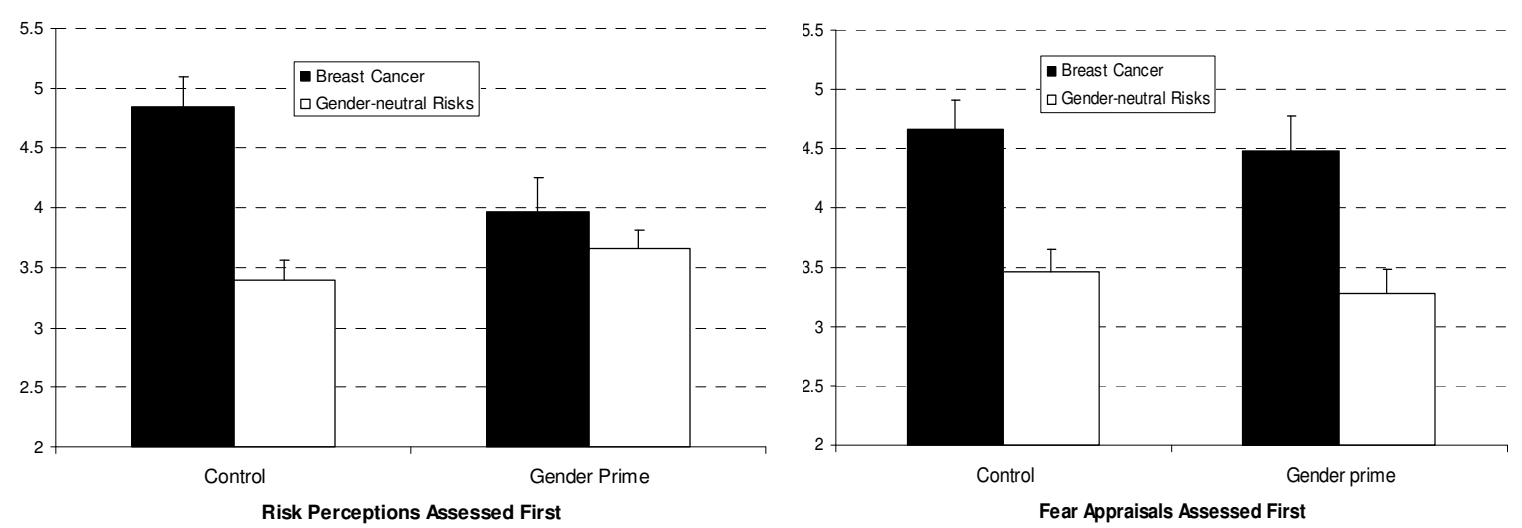

\section{GENERAL DISCUSSION}

Despite the large body of literature devoted to understanding the psychological processes involved in the estimation of perceived vulnerability, the relationship between risk estimates and self-identity is still unclear. This paper explored how 
inherent characteristics of a risk interact with self-identity salience to influence estimates of perceived vulnerability. In particular, we investigated how and under which conditions the salience of a certain identity trait (e.g., gender) can influence one's perceived susceptibility to risks associated with this trait (e.g., breast cancer).

Estimates of personal risk are constructed by individuals based on environmental cues and personal experience (Gerend et al. 2004). This illustrates the need to consider social cognition in understanding the processes involved in assessing one's vulnerability to personal risks. It has long been assumed that greater cognitive accessibility should result in higher likelihood estimates for uncertain events (Tversky and Kahneman 1973). Across a number of studies, we provided evidence for the operation of a different mechanism, one that is both intriguing from a theoretical point of view - as it leads to predictions opposite to those of a cognitive accessibility account — and important from a substantive point of view—as it has implications for the design and implementation of health campaigns. We predicted that an increase in the salience of a central identity aspect (gender) associated with a personal risk (breast- and ovarian cancer) can trigger selective defensive mechanisms of risk minimization. We found that priming participants' own gender led to reduced perceived vulnerability to breast cancer, and ovarian cancer donations, but that it did not affect perceptions of gender-neutral risks.

Implications for Defense Mechanisms

In contemporary thinking about defense mechanisms, an important function is seen to be the protection of the self and self-esteem (Cramer 2000). This is exemplified by the extensive body of research on Terror Management Theory (TMT, Pyszczynski et al. 2004). According to TMT, people are motivated to pursue positive 
self-evaluations because self-esteem provides a buffer against the omnipresent potential for anxiety engendered by the uniquely human awareness of mortality. A wealth of empirical research has shown that increasing the salience of one's mortality leads to a wide array of self-esteem bolstering effects, such as identification with one's culture and relevant in-groups and increased pride in one's talents. This literature has shown that the need to bolster self-esteem triggered by the existential fear of death can lead individuals to engage in risky behaviors, such as reckless driving and unsafe sex (Ben-Ari 2004; Ben-Ari, Florian, and Mikulincer 1999). The current set of studies adds to this literature by highlighting a new context in which maladaptive responses can be triggered by ego threat.

Self-esteem is derived from many individual-specific dimensions (Crocker and Wolfe 2001). Individuals have (limited) freedom to choose the domains on which they stake their self-esteem and the salience of different domains will be context dependent. Some domains may be more central than others to an extent that they will almost unavoidably be incorporated in one's sense of self-esteem and previous research has documented the importance of women's sense of gender identity in the development of their self-esteem (Andersen and Cyranowski 1994). Our findings indicate that the prominence of such central dimensions in one's self-definition can be further increased and has immediate motivational consequences by shielding the self from potential threats to this central dimension. To our knowledge, our studies are the first to manipulate the salience of a central dimension of identity to demonstrate that this triggers selective defense mechanisms restricted to protecting the activated dimension: defensive risk minimization was limited to the gender-specific risk estimates and did not affect risk estimates in general. 
Implications for Priming Research

Early studies on priming lent considerable support to spreading activation models of our knowledge system as a distributed network of semantically and associatively linked concepts (Collins and Loftus 1975). Generally, activating (priming) a concept leads to an increased accessibility of related concepts and hence an increased probability that these will be manifested behaviorally (Kruglanski 1996). As a warning against 'simplistic' expectations regarding priming effects, however, several sources of contrast effects in priming have been identified. It has been shown that extreme primes can lead to opposite effects from more moderate primes (Herr, Sherman and Fazio 1983), that awareness of the prime can lead to contrast effects (Lombardi, Higgins, and Bargh 1987) as can priming people with exemplars instead of stereotypes or traits (Moskowitz and Skurnik 1999). Recently, the importance of taking into account motivational processes when studying priming effects has been demonstrated by the research of Arndt et al. (2007) who showed that priming people with cancer can lead to suppression, instead of increased accessibility, of death-related thoughts when participants enjoy sufficient processing capacity. Our results add to this literature by showing how increased self-relevance enhances the probability of motivational, defensive mechanisms interfering with the basic priming effect. This process was most distinct in the linear trend observed in experiment 3. Here we found that women's breast cancer risk estimates were directionally higher in the general gender condition than in the control condition, as would be expected from a simple priming effect which would increase the accessibility of gender-related concepts when gender is primed. Only when personal relevance increased by specifically priming participants' own gender, did the motivational defense mechanism of risk 
minimization overrule the basic priming effect. This suggests ego threat as a new moderator of basic priming effects.

Implications for Health Communication

Health campaigns aimed at increasing women's breast screening behavior often stress women's vulnerability to breast cancer using images and appeals related to the female sex and to femininity. Our results lead to the counterintuitive conclusion that the use of these appeals might have adverse effects on female's risk perceptions for breast cancer. These appeals almost inevitably stress womanhood or women's sense of gender identity and along with it the relative importance of this identity aspect for their self-concept. Our findings indicate that such an increase in gender identity salience can trigger defensive mechanisms of risk minimization, thus potentially attenuating or even reversing a campaign's intended consequences. For example, experiment 2 found that this had a detrimental effect on donating behavior. The experiments presented above provide a number of suggestions on how to reduce the likelihood of defensive mechanisms interfering with the intended aim of health campaigns. Experiment 3 suggests that breast cancer awareness campaigns might avoid triggering defensive mechanisms when the appeal is not directly linked to women's gender identity. In practice, this might be accomplished by designing breast cancer awareness campaigns that focus on directly altering behavior, for example by trying to impose implementation intentions for screening behavior. In addition, the results of experiment 4 suggest that eliciting explicit fear appraisal could be a way to reduce the impact of defensive mechanisms. This could be accomplished through textual information (e.g., "How afraid are you of breast cancer?”). 
Andersen, Barbara L. and Jill M. Cyranowski (1994), "Women's Sexual Self-schema," Journal of Personality and Social Psychology, 67 (December), 1079-1100.

Arndt, Jamie, Alison Cook, Jamie L. Goldenberg, and Cathy R. Cox (2007), "Cancer and the Threat of Death: The Cognitive Dynamics of Death-thought Suppression and its Impact on Behavioral Health Intentions," Journal of Personality and Social Psychology, 92 (January), 12-29.

Baumeister, Roy F., Karen Dale, and Kristin L. Sommer (1998), "Freudian Defense Mechanisms and Empirical Findings in Modern Social Psychology: Reaction Formation, Projection, Displacement, Undoing, Isolation, Sublimation, and Denial," Journal of Personality, 66 (December), 1081-1124.

Bem, Sandra L. (1981), "Gender Schema Theory: A Cognitive Account of Sex Typing," Psychological Review, 88, 354-364.

Ben-Ari, Orit Taubman (2004), "Intimacy and Risky Sexual Behavior: What Does it Have to do With Death?," Death Studies, 28 (November), 865-887.

Ben-Ari, Orit Taubman, Victor Florian, and Mario Mikulincer (1999), "The Impact of Mortality Salience on Reckless Driving: A Test of Terror Management Mechanisms," Journal of Personality and Social Psychology, 76 (January), 35-45.

Collins, Allan M. and Elizabeth F. Loftus (1975), "A Spreading-activation Theory of Semantic Processing," Psychological Review, 82, 407-428.

Cramer, Phebe (2000), "Defense Mechanisms in Psychology Today: Further Processes for Adaptation," American Psychologist, 55 (June), 637-646.

Crocker, Jennifer and Connie T. Wolfe (2001), "Contingencies of Self-worth," Psychological Review, 108 (July), 593-623.

Fallowfield, Lesley and Angela Hall (1991), "Psychosocial and Sexual Impact of Diagnosis and Treatment of Breast Cancer," British Medical Bulletin, 47 (April), 388-399.

Gerend, Mary A., Leona S. Aiken, Stephen G. West, and Mindy J. Erchull (2004), "Beyond Medical Risk: Investigating the Psychological Factors Underlying Women's Perceptions of Susceptibility to Breast Cancer, Heart Disease, and Osteoporosis," Health Psychology, 23 (May), 247-258.

Hall, Lynda (1997), "Re-figuring Marked Bodies on the Borders: Breast Cancer and 'Femininity'," Journal of Gay, Lesbian, and Bisexual Identity, 2 (2), 101-121.

Han, Seunghee, Jennifer S. Lerner, and Dacher Keltner (2007), "Feelings and Consumer Decision Making: The Appraisal-Tendency Framework," Journal of Consumer Psychology, 17 (3), 158-168.

Harris, Peter R. and Lucy Napper (2005), "Self-affirmation and the Biased Processing of Threatening Health-risk Information," Personality and Social Psychology Bulletin, 31 (September), 1250-1263.

Herr, Paul M., Steven J. Sherman, and Russell H. Fazio (1983), "On the Consequences of Priming: Assimilation and Contrast Effects," Journal of Experimental Social Psychology, 19 (4), 323-340.

Hertwig, Ralph, Thorsten Pachur, and Stephanie Kurzenhauser (2005), "Judgments of Risk Frequencies: Tests of Possible Cognitive Mechanisms," Journal of Experimental Psychology: Learning, Memory, and Cognition, 31 (July), 621642. 
Jemmott, John B., Peter H. Ditto, and Robert T. Croyle (1986), "Judging Health Status: Effects of Perceived Prevalence and Personal Relevance," Journal of Personality and Social Psychology, 50 (5), 899-905.

Kruglanski, Arie W. (1996), "Goals as Knowledge Structures," in Psychology of Action: Linking Cognition and Motivation to Behavior, eds. P. M. Gollwitzer and J. A. Bargh. New York: Guilford Press, 599-619.

Lazarus, Richard S. (2000), "Toward Better Research on Stress and Coping," American Psychologist, 55 (June), 665-673.

Liberman, Akiva and Shelly Chaiken (1992), "Defensive Processing of Personally Relevant Health Messages," Personality and Social Psychology Bulletin, 18 (December), 669-679.

Lombardi, Wendy J., E. Tory Higgins, and John A. Bargh (1987), "The Role of Consciousness in Priming Effects on Categorization: Assimilation versus Contrast as a Function of Awareness of the Priming Task," Personality and Social Psychology Bulletin, 13 (3), 411-429.

Markus, Hazel and Ziva Kunda (1986), "Stability and Malleability of the Selfconcept," Journal of Personality and Social Psychology, 51 (4), 858-866.

Markus, Hazel and Paula Nurius (1986), "Possible Selves," American Psychologist, 41 (9), 954-969.

Markus, Hazel and Elissa Wurf (1987), "The Dynamic Self-concept: A Socialpsychological Perspective," Annual Review of Psychology, 38, 299-337.

McClelland, James L. (2000), "Connectionist Models of Memory," in The Oxford Handbook of Memory, eds. E. Tulving and F. E. M. Craik. Oxford: Oxford University Press, 583-596.

Moskowitz, Gordon B. and Ian W. Skurnik (1999), "Contrast Effects as Determined by the Type of Prime: Trait versus Exemplar Primes Initiate Processing Strategies that Differ in how Accessible Constructs are Used," Journal of Personality and Social Psychology, 76 (June), 911-927.

Pyszczynski, Tom, Sheldon Solomon, Jeff Greenberg, Jamie Arndt, and Jeff Schimel (2004), "Why Do People Need Self-esteem? A Theoretical and Empirical Review," Psychological Bulletin, 130 (May), 435-468.

Raghubir, Priya and Geeta Menon (1998), "AIDS and Me, Never the Twain Shall Meet: The Effects of Information Accessibility on Judgments of Risk and Advertising Effectiveness," Journal of Consumer Research, 25 (June), 52-63.

Schwarz, Norbert and Gerald L. Clore (1983), "Mood, Misattribution, and Judgments of Well-being: Informative and Directive Functions of Affective States," Journal of Personality and Social Psychology, 45, 513-523.

Tversky, Amos and Daniel Kahneman (1973), "Availability: A Heuristic for Judging Frequency and Probability," Cognitive Psychology, 5 (2), 207-232. 


\section{Publications in the Report Series Research* in Management}

\section{ERIM Research Program: "Marketing"}

\section{8}

Experts' Stated Behavior

Youssef Boulaksil and Philip Hans Franses

ERS-2008-001-MKT

http://hdl.handle.net/1765/10900

The Value of Analogical Reasoning for the Design of Creative Sales Promotion Campaigns: A Case-Based Reasoning Approach

Niek A.P. Althuizen and Berend Wierenga

ERS-2008-006-MKT

http://hdl.handle.net/1765/11289

Shopping Context and Consumers' Mental Representation of Complex Shopping Trip Decision Problems

Benedict G.C. Dellaert, Theo A. Arentze and Harry J.P. Timmermans

ERS-2008-016-MKT

http://hdl.handle.net/1765/11812

Modeling the Effectiveness of Hourly Direct-Response Radio Commercials

Meltem Kiygi Calli, Marcel Weverbergh and Philip Hans Franses

ERS-2008-019-MKT

http://hdl.handle.net/1765/12242

Choosing Attribute Weights for Item Dissimilarity using Clikstream Data with an Application to a Product Catalog Map

Martijn Kagie, Michiel van Wezel and Patrick J.F. Groenen

ERS-2008-024-MKT

http://hdl.handle.net/1765/12243

The Effect of Superstar Software on Hardware Sales in System Markets

Jeroen L.G. Binken and Stefan Stremersch

ERS-2008-025-MKT

http://hdl.handle.net/1765/12339

Sales Growth of New Pharmaceuticals Across the Globe: The Role of Regulatory Regimes

Stefan Stremersch and Aurélie Lemmens

ERS-2008-026-MKT

http://hdl.handle.net/1765/12340

When Intelligence is (Dys)Functional for Achieving Sales Performance

Willem J. Verbeke, Frank D. Belschak, Arnold B. Bakker, and Bart Dietz

ERS-2008-034-MKT

http://hdl.handle.net/1765/12633

Path Dependencies and the Long-term Effects of Routinized Marketing Decisions

Paul Farris, Willem J. Verbeke, Peter Dickson and Erjen van Nierop

ERS-2008-035-MKT

http://hdl.handle.net/1765/12634

Does Irritation Induced by Charitable Direct Mailings Reduce Donations?

Merel van Diepen, Bas Donkers and Philip Hans Franses

ERS-2008-036-MKT

http://hdl.handle.net/1765/12704 
Brain Mechanisms of Persuasion: How "Expert Power" Modulates Memory and Attitudes

Vasily Klucharev, Ale Smidts and Guillén Fernández

ERS-2008-038-MKT

http://hdl.handle.net/1765/12784

Moderating Factors of Immediate, Dynamic, and Long-run Cross-Price Effects

Csilla Horváth and Dennis Fok

ERS-2008-042-MKT

http://hdl.handle.net/1765/12901

Why, How and When Do Prices Land? Evidence from the Videogame Industry

Carlos Hernandez-Mireles, Dennis Fok and Philip Hans Franses

ERS-2008-044-MKT

http://hdl.handle.net/1765/12900

Situation-Based Shifts in Consumer Web Site Benefit Salience: The Joint Role of Affect and Cognition

Sonja Wendel and Benedict G.C. Dellaert

ERS-2008-050-MKT

http://hdl.handle.net/1765/13179

Including Item Characteristics in the Probabilistic Latent Semantic Analysis Model for Collaborative Filtering

Martijn Kagie, Matthijs van der Loos and Michiel van Wezel

ERS-2008-053-MKT

http://hdl.handle.net/1765/13180

Cross-National Logo Evaluation Analysis: An Individual Level Approach

Ralf van der Lans, Joseph A. Cote, Catherine A. Cole, Siew Meng Leong, Ale Smidts, Pamela W. Henderson, Christian Bluemelhuber, Paul A. Bottomley, John R. Doyle, Alexander Fedorikhin, M. Janakiraman, B. Ramaseshan, and Bernd $\mathrm{H}$. Schmitt

ERS-2008-055-MKT

http://hdl.handle.net/1765/13181

Sales and Sincerity: The Role of Relational Framing in Word-of-Mouth Marketing

Mirjam A. Tuk, Peeter W.J. Verlegh, Ale Smidts and Daniel H.J. Wigboldus

ERS-2008-056-MKT

http://hdl.handle.net/1765/13183

Interpersonal Relationships Moderate the Effect of Faces on Person Judgments

Mirjam A. Tuk, Peeter W.J. Verlegh, Ale Smidts and Daniel H.J. Wigboldus

ERS-2008-057-MKT

http://hdl.handle.net/1765/13185

Evaluative Conditioning 2.0: Referential versus Intrinsic Learning of Affective Value Steven Sweldens, Stijn M.J. van Osselaer, and Chris Janiszewski

ERS-2008-062-MKT

http://hdl.handle.net/1765/13612

Gender Identity Salience and Perceived Vulnerability to Breast Cancer

Steven Sweldens, Stefano Puntoni, and Nader Tavassoli

ERS-2008-063-MKT

http://hdl.handle.net/1765/13613

The Emotional Information Processing System is Risk Averse: Ego-Depletion and Investment Behavior

Bart De Langhe, Steven Sweldens, Stijn M.J. van Osselaer, and Mirjam Tuk

ERS-2008-064-MKT

http://hdl.handle.net/1765/13614 
The Moderating Roles of Relationship Quality and Dependency in Retailers' New Product Adoption Decisions Yvonne M. van Everdingen, Laurens M. Sloot, and Peter C. Verhoef

ERS-2008-065-MKT

http://hdl.handle.net/1765/13615

Modeling Global Spill-Over of New Product Takeoff

Yvonne M. van Everdingen, Dennis Fok, Stefan Stremersch

ERS-2008-067-MKT

http://hdl.handle.net/1765/13616

* A complete overview of the ERIM Report Series Research in Management: https://ep.eur.nl/handle/1765/1

ERIM Research Programs:

LIS Business Processes, Logistics and Information Systems

ORG Organizing for Performance

MKT Marketing

F\&A Finance and Accounting

STR Strategy and Entrepreneurship 